\title{
Autumn establishment of lucerne (Medicago sativa L.) inoculated with four different carriers of Ensifer meliloti at four sowing dates.
}

\author{
D.B.S BLACK and D.J. MOOT \\ Faculty of Agriculture and Life Science, Lincoln University, P.O. Box 85084, Lincoln \\ Derrick.Moot@lincoln.ac.nz
}

\begin{abstract}
The effects of autumn sowing dates (26 January 2012, 21 February 2012, 15 March 2012, 3 April 2012) and inoculant carriers (ALOSCA $\AA$, coated seed, Nodulator ${ }^{\circledR}$ and peat slurry) on lucerne (Medicago sativa L.) establishment and yield were studied at Lincoln University on a variable Templeton silt loam soil. For the 2012/13 regrowth season the January (14.7 t/ha) sowing date yielded more dry matter (DM) than the March (11.2 t/ha) and April (7.3 t/ha) sowing dates, and February (13.2 t/ha) was intermediate. All four inoculation carriers resulted in increased DM and nitrogen $(\mathrm{N})$ yields compared with the bare seed control. A comparison of the peat inoculated and bare seed treatments indicated an extra $335 \mathrm{~kg} \mathrm{~N} / \mathrm{ha}$ was removed in herbage from the inoculated treatments. Results highlight the importance of rhizobia, biological nitrogen fixation, and seed inoculation when sowing lucerne into soil with no paddock history of lucerne.

Keywords: alfalfa, ALOSCA $\AA$, bare seed, biological nitrogen fixation, coated seed Nodulator ${ }$, peat slurry treated seed, rhizobia.
\end{abstract}

\section{Introduction}

Spring establishment of lucerne is recommended to ensure crops are sown into warm soil (Wynn-Williams 1982) and have a full growing season to establish their root system (Teixeira et al. 2007b). Wigley et al. (2012) reported the highest yields as seedling crops were from those sown in early November. Crops sown in January and February had the lowest yields in their establishment year, and yields remained lower for these crops in the subsequent first full year of production. It seems likely that the partitioning priority of the summer sown crops continued towards roots compared with shoots in the spring of that second year (Teixeira et al. 2007b). It is not recommended to establish lucerne crops in autumn, because the declining temperatures and photoperiod make crops vulnerable to weed invasion. Despite this, autumn is the preferred time for pasture establishment in New Zealand because it fits with many other farm operations. Thus, this experiment used sowing dates from summer into autumn to examine the effects on the yield of lucerne crops in their establishment and first full regrowth seasons.
A further consideration in the establishment of legumes is the need to provide viable rhizobia to ensure nitrogen fixation. Recent research has questioned the need for inoculation of perennial legumes (Lowther \& Kerr 2011). However, inoculation of lucerne has received less attention and is generally accepted to be required, with several formulations commercially available for delivery. Wigley et al. (2012) found that coated seed resulted in higher plant populations at establishment than other inoculation methods, but this did not result in any dry matter yield advantage. In the first full year of production, crops established with peat slurry had the highest yield on a stony soil at Ashley Dene research farm at Lincoln University. In that experiment (Wigley et al. 2012), and a similar experiment on a deeper soil (Khumalo 2012), the mineralisable $\mathrm{N}$ levels appeared to be adequate to grow the initial seedling lucerne crops. In the second production year at Ashley Dene, bare seed crops continued to produce yields equivalent to the coated and granular inoculant methods, but these were lower than those obtained with the peat inoculant. In both experiments there was a history of lucerne crops having been grown in the experimental paddocks within the previous five years. DNA analyses suggested the indigenous population of Ensifer meliloti nodulated the seedlings from bare seed and fixed sufficient nitrogen to maintain crop yields. It is unclear, however, whether the E. meliloti is sufficiently widespread to nodulate crops grown in soils with no previous lucerne history. Therefore the current experiment aimed to determine the impact of autumn sowing and different delivery methods of inoculant on the yield and quality of lucerne grown in a paddock with no previous history of lucerne.

\section{Materials and methods}

\section{Experimental site}

This experiment was established at Lincoln University, Canterbury $\left(43^{\circ} 38^{\prime} \mathrm{S}\right.$ and $\left.172^{\circ} 28^{\prime} \mathrm{E}\right)$ on a variable Templeton silt loam (Kear et al. 1967) with moderate to high fertility. The paddock came out of 'Regatta' barley in August 2011 and was top worked with the rotacrumbler, once in August, then again in September. At the end of September the paddock was Dutch harrowed and rolled. Subsequently Roundup transorb ${ }^{\circledR}$ was applied at $2 \mathrm{l} / \mathrm{ha}$, equivalent to $1080 \mathrm{~g}$ glyphosate/ha, 

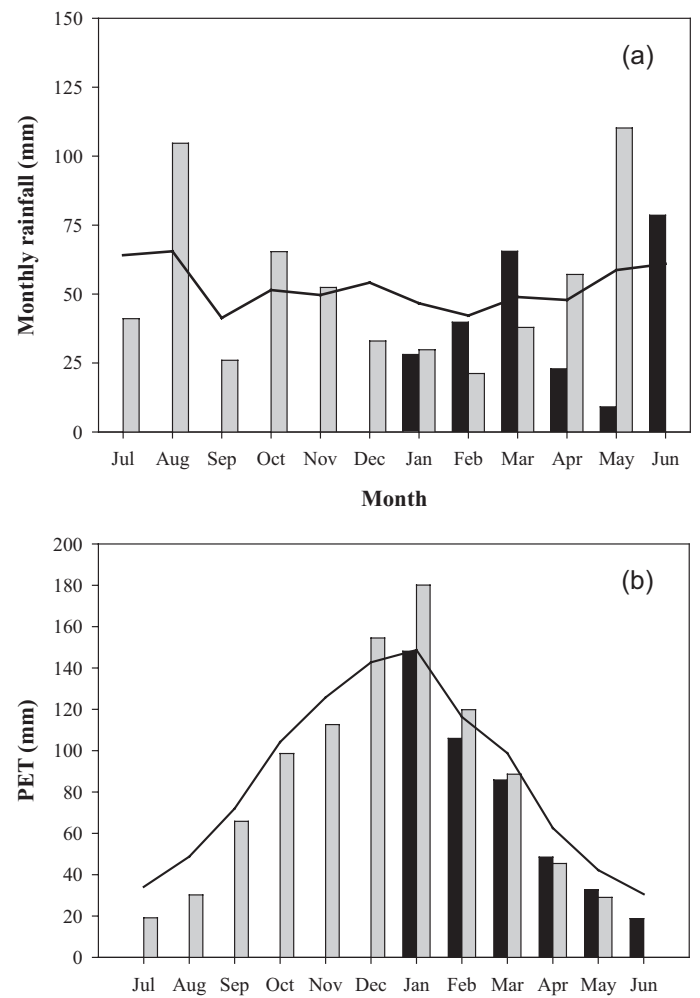

Month

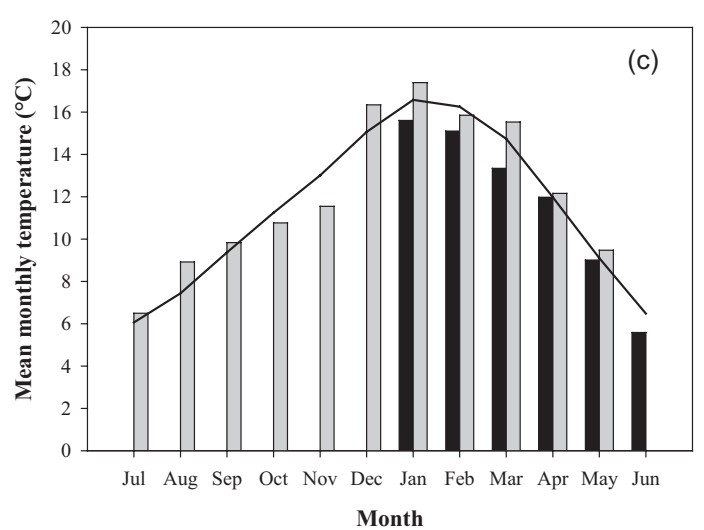

Figure 1 (a) Monthly rainfall from January 2012-June 2012 (घ), and July 2012-May 2013 (घ) at Broadfields weather station, Lincoln. The long term mean from $1975-2012$ is also given (-).(b) potential evapotranspiration (PET) from January 2012June 2012 (घ), and July 2012-May 2013 (घ) at Broadfields weather station, Lincoln. The long term mean from 1975- 012 is also given (-).(c) mean monthly temperature from January 2012June 2012 (匹), and July 2012-May 2013 (๘) at Broadfields weather station, Lincoln. The long term mean from 1975- 012 is also given $(-)$. and a week later the paddock was reworked with the rota-crumbler. Soil tests revealed a $\mathrm{pH}$ of 5.9, and thus 4 tonnes lime/ha was applied in October 2011 and top worked with a rota-crumbler. After two further sprays with 1080 g glyphosate/ha, on 25 November 2011 and on 11 January 2012, the paddock was rotary hoed and then rolled on 16 January 2012. Soil tests revealed a deficiency in sulphate sulphur, so on 17 January 2012 Maxi Sulphur Super (0-5-0-47) was applied at a rate of $100 \mathrm{~kg} / \mathrm{ha}$.

\section{Experimental design}

A split plot design with three replicates was sown with four 2012 sowing dates (SD) as main plots (SD1 = 26 January 2012; SD2 = 21 February 2012; SD3 $=15$ March 2012 and SD4 3 April). Four carriers of rhizobial inoculum were the subplots: coated seed; peat slurry; Nodulator ${ }^{\circledR}$ and ALOSCA ${ }^{\circledR}$ granules. A bare seed control was also sown.

\section{Inoculation and sowing}

The European-bred 'Force 4' cultivar was used in this experiment. It was introduced to New Zealand in 2006 (D. Walsh pers. comm.) and has a dormancy rating of 4 , meaning it is moderately winter dormant.

Lucerne at $10.5 \mathrm{~kg} / \mathrm{ha}$ was sown as (i) bare seed (ii) bare seed with ALOSCA ${ }^{\circledR}$ bentonite granules containing E. meliloti (Carr et al. 2006) sown through the drill at the recommended rate of $10.5 \mathrm{~kg} / \mathrm{ha}$ (iii) bare seed with Nodulator ${ }^{\circledR}$ granules sown through the drill at the recommended rate of $6 \mathrm{~kg} / \mathrm{ha}$ (iv) bare seed coated with E. meliloti in a peat slurry (v) commercially provided coated seed that contained E. meliloti, a contact fungicide to target Pythium spp., molybdenum and lime. The seed and coating combined to give a sowing rate of $17 \mathrm{~kg} / \mathrm{ha}$, equivalent to a $10.5 \mathrm{~kg} / \mathrm{ha}$ bare seed sowing rate. An Øyjord cone seeder, with $0.15 \mathrm{~m}$ gaps between rows, was used to sow $6.3 \times 10 \mathrm{~m}\left(63 \mathrm{~m}^{2}\right)$ plots with $0.5 \mathrm{~m}$ gaps between them. To limit possible contamination the sowing order was: bare seed, ALOSCA ${ }^{\circledR}$ treatment, Nodulator ${ }^{\circledR}$ treatment, coated seed and lastly peat slurry treatment.

\section{Rainfall and climate}

Rainfall, Penman's potential evapotranspiration (PET), and temperature data for the period January 2012-May 2013 were recorded at Broadfields meteorological station, accessed from NIWA's website (Figure 1). During the experiment there were seasonal patterns typical of the long term means except for a lower than average rainfall in the summer of 2013 with consequently higher rates or PET. 


\section{Measurements}

Soil mineral $N$

In early September 2012, bulked soil samples from each plot were collected to $0.15 \mathrm{~m}$ and analysed for ammonium and nitrate by $\mathrm{KCl}$ extraction and flow injection analysis as prescribed by Blakemore et al. (1987) and Clough et al. (2001).

\section{Seedling emergence, plant populations and tap root numbers}

Seedling emergence was defined by the appearance of a spade leaf. Three fixed $1 \mathrm{~m}$ drill row lengths were chosen at random and observed every third day from sowing until no new plants emerged. Initial plant populations were estimated from these measurements 15 days after sowing. Plant populations were also measured by excavating $0.2 \mathrm{~m}^{2}$ quadrats to a depth of $0.3 \mathrm{~m}$ and the number of tap roots counted in July 2012 and May 2013.

\section{Shoot dry matter yield}

During establishment, seedling crops were left to grow for as long as possible prior to winter. Only crops from SD1 formed buds in the majority of plants, and only crops from SD1 and SD2 had sufficient herbage to be harvested mechanically to measure yield in the first winter. Seedlings from SD3 and SD4 were of insufficient height $(<50 \mathrm{~mm})$ to be harvested. There was no grazing at any time in the experiment specifically to avoid complications from nutrient deposits affecting plant growth and nitrogen fixation.

From spring 2012 until autumn 2013, six harvests were made for SD1 and SD2 and five harvests were made for SD3 and SD4. The first yield for SD4 was estimated through non-destructive height measurements. Dry matter (DM) yields were determined by taking $0.2 \mathrm{~m}^{2}$ quadrat cuts and drying in an oven for 72 hours at $65^{\circ}$ C. All full plot harvests were subsequently carried out mechanically with a cut and carry regime when at least $50 \%$ of plants were either in "bud" or were at risk of lodging ( $>0.4 \mathrm{~m}$ tall). January and February sowing dates were harvested concurrently and at different dates to March and April sowing dates until the first cut of 2013 when water became limiting (Figure 1a) and harvests for all sowings dates were synchronised.

\section{Dry matter partitioning in perennial organs}

Root DM yields were determined from root digs to a depth of $300 \mathrm{~mm}$. The roots were cut and separated into the top $50 \mathrm{~mm}$ and remaining $250 \mathrm{~mm}$ of the root profile before drying in an oven for 5 days at $65^{\circ} \mathrm{C}$.

\section{Near-infrared spectroscopy}

Near-infrared spectroscopy (NIR) was used for nutritive analysis of nitrogen $(\mathrm{N})$ and metabolisable energy (ME) from above-ground harvests for the peat-treated and bare seed treatments. Each sample was prepared by grinding the entire dry weight sample twice: first through an $8 \mathrm{~mm}$ sieve on a Cyclotec grinder and then through a $1 \mathrm{~mm}$ sieve on a Retsch ZM 200 grinder.

\section{Statistical analysis}

Analysis of treatment effects by split plot ANOVA was performed using Genstat (15th Ed, VSN International Ltd.). Where $\mathrm{P} \leq 0.05$, Fisher's protected least significant difference (LSD) tests were employed to separate mean values.

\section{Results and discussion \\ Plant population at establishment and the end of the 2012-13 growth season}

SD1 had a plant population of 158 plants $/ \mathrm{m}^{2} 15$ days after sowing, which was the lowest $(\mathrm{P}=0.004)$ at emergence. Two blocked coulters in the drill led to a $25 \%$ lower sowing rate for SD1, which explains, in part, the lower plant population. A lower soil moisture content for SD1, relative to the other sowing dates, may also explain the lower plant population at establishment. There was no difference in plant population between the other sowing dates with over 350 plants $/ \mathrm{m}^{2}$ established.

By July 2012, SD1 had 144 plants $/ \mathrm{m}^{2}$, which was still fewer $(\mathrm{P}=0.002)$ than the other three SDs. These lower plant populations, however, did not affect DM yield in the first full regrowth season. Wynn-Williams (1982) at Lincoln indicated that, in the absence of major pests and diseases, a plant population of 30 plants $/ \mathrm{m}^{2}$ was sufficient in the regrowth season, and the lucerne stand life was then independent of initial seeding rates. These results were confirmed by Moot et al (2012) who showed no yield differences in year 6 with plant populations of 80 plants $/ \mathrm{m}^{2}$ for crops sown at 7-16 $\mathrm{kg} / \mathrm{ha}$. A high degree of plasticity exists, whereby the number of shoots per plant increases to compensate for lower plant numbers, regardless of initial sowing conditions and defoliation management (Teixeira et al. 2007a).

\section{Dry matter yield}

In the establishment season of autumn 2012, SD1 yielded $1500 \mathrm{~kg} \mathrm{DM} / \mathrm{ha}$ and SD2 yielded $817 \mathrm{~kg} \mathrm{DM} /$ ha, whilst SD3 and SD4 were still seedlings $<50 \mathrm{~mm}$ in height. The total yield from sowing (Figure 2a) to the end of the first regrowth year was $16200 \mathrm{~kg} \mathrm{DM} / \mathrm{ha}$ for $\mathrm{SD} 1$, which was more than $(\mathrm{P}<0.05)$ the $14000 \mathrm{~kg} \mathrm{DM} /$ ha from SD2. This in turn was greater $(\mathrm{P}<0.05)$ than $\mathrm{SD} 3$, with the lowest $(\mathrm{P}<0.05)$ yield from SD4. 

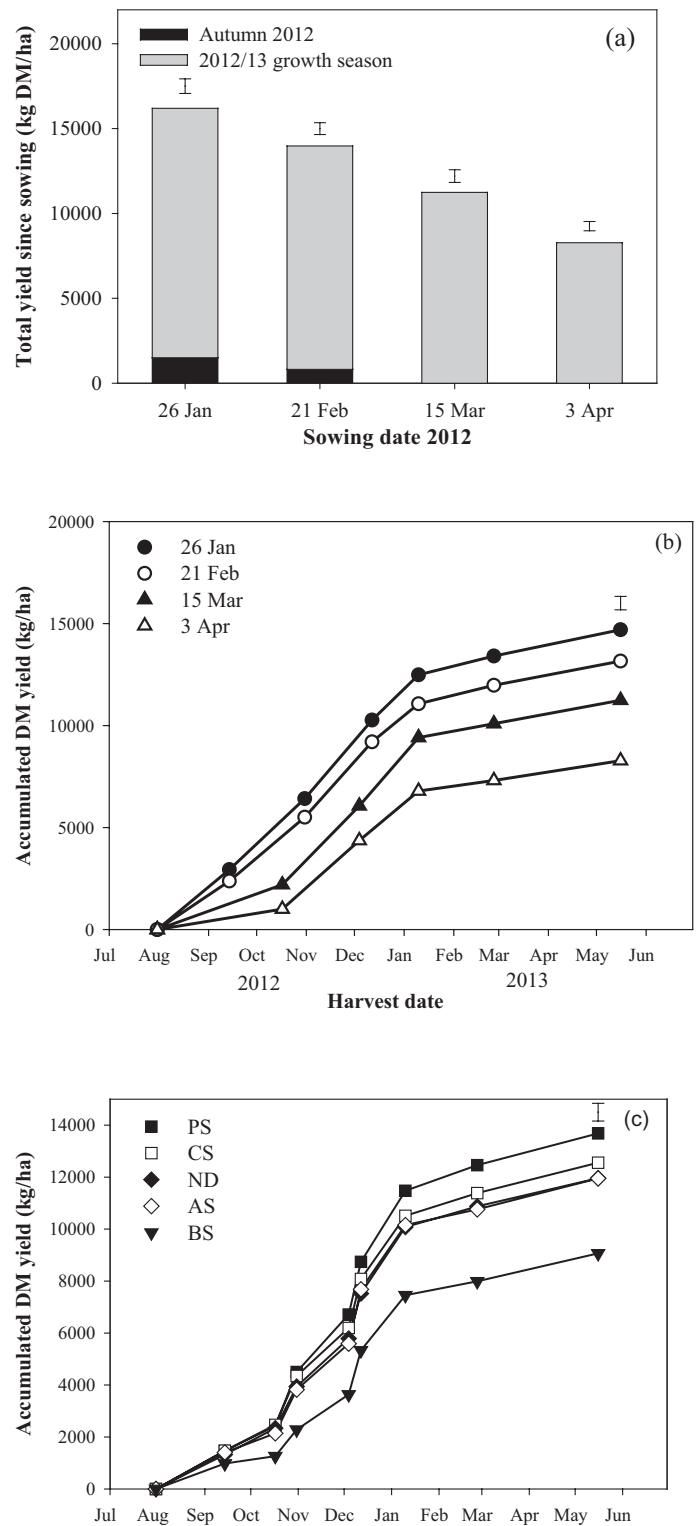

Figure 2. Accumulated dry matter (DM) production of 'Force 4' lucerne since sowing (a) and for the 2012/13 growth season when sown (b) on four different sowing dates in 2012 with (c) five different seed treatments: PS (peat seed), CS (coated seed), ND (Nodulator $\AA$ ), AS (ALOSCA $®$ ) and BS (bare seed). Error bars are SEM for the main treatment effect shown.

The remainder of the results all pertain to the 2012/13 regrowth season. SD1 and SD2 were first harvested on 14 September (Figure 2b). The average yield was $2660 \pm 138 \mathrm{~kg} \mathrm{DM} / \mathrm{ha}$ at this time and there was no inoculation effect. For the second cut, on 31 October,

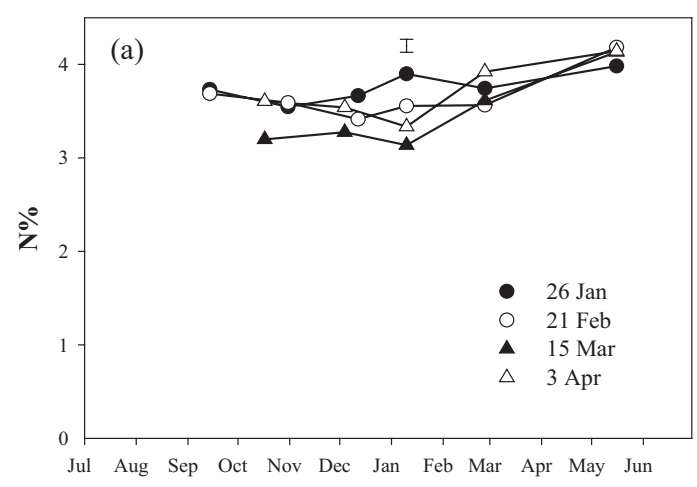

Harvest date

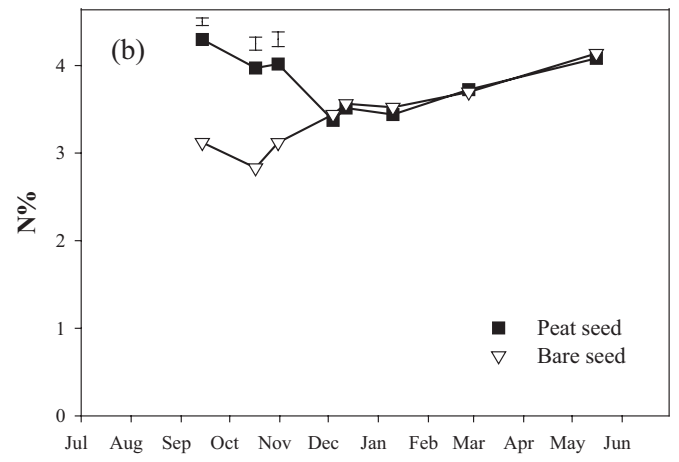

Harvest date

Figure 3. N\% of 'Force 4' lucerne for the 2012/13 growth season when (a) sown on four different dates (2012) with (b) peat seed or bare seed treatments. Error bars are SEM for the main treatment effect shown.

the bare seed crops yielded $2030 \mathrm{~kg} \mathrm{DM} / \mathrm{ha}$ which was less than $(\mathrm{P}<0.01)$ all other seed treatments. In comparison, peat-treated seed yielded $4140 \mathrm{~kg} \mathrm{DM} /$ ha. By the third harvest on 12 December there was no inoculation effect and the mean treatment yield was 3 $780 \pm 132 \mathrm{~kg} \mathrm{DM} / \mathrm{ha}$.

SD3 and SD4 were first harvested on 17 October. SD3 produced $2200 \mathrm{~kg} \mathrm{DM} / \mathrm{ha}$ or double that from $\mathrm{SD} 4(\mathrm{P}<0.01)$. The bare seed treatment produced the lowest $(\mathrm{P}<0.001)$ yield of $573 \mathrm{~kg} \mathrm{DM} / \mathrm{ha}$. At the 4 December harvest date there were no yield differences amongst inoculation treatments.

After the final three synchronised harvests in 2013, sowing date and seed treatment affected accumulated annual DM yield (Figures $2 \mathrm{~b} ; 2 \mathrm{c}$ ). SD1 had the highest yield averaging $14700 \mathrm{~kg} \mathrm{DM} / \mathrm{ha}$, which was $31 \%$ higher than SD3 $(\mathrm{P}<0.05)$. SD4 had the lowest $(\mathrm{P}<0.05)$ yield of $8280 \mathrm{~kg} \mathrm{DM} / \mathrm{ha}$. Similarly, Wigley et al. (2012) observed that delaying sowing from spring to autumn reduced herbage yield in the subsequent regrowth season probably as a result of additional partitioning requirements for autumn sown crops in the second year 

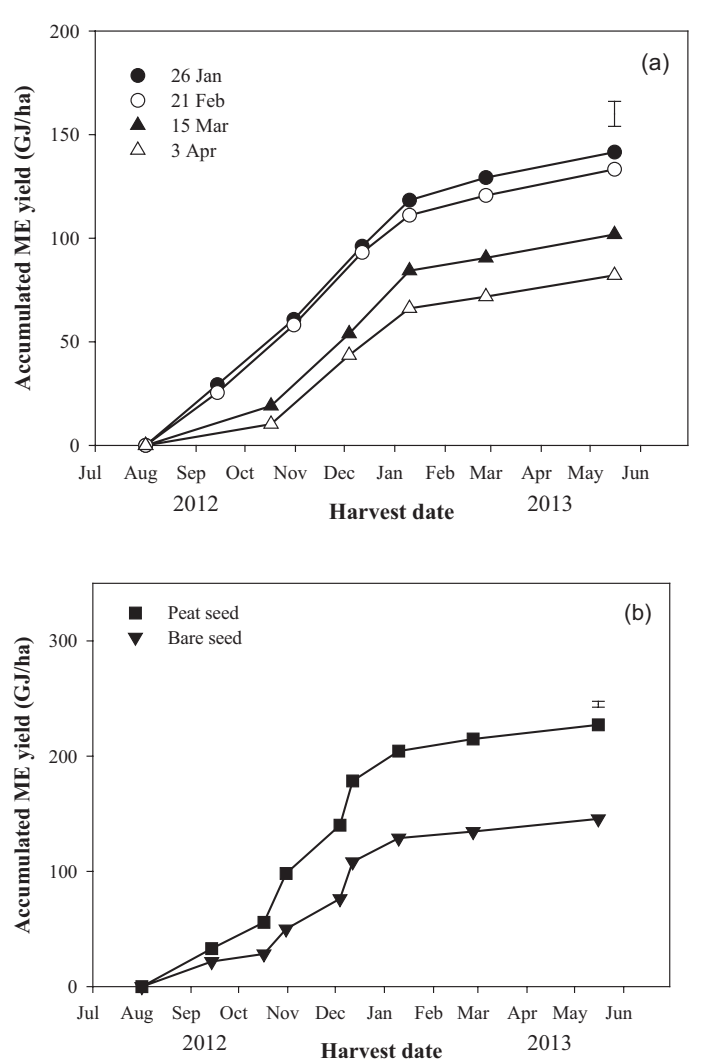

Figure 4. Accumulated metabolisable energy (ME) yield of 'Force 4' lucerne for the 2012/13 growth season depicting (a) four different sowing dates (2012) and (b) peat seed and bare seed treatments. Error bars are SEM for the main treatment effect shown.

All inoculated seed treatments gave higher $(\mathrm{P}<0.001)$ DM yields than the bare seed control (Figure 2c). This highlights the importance of inoculating seeds when growing lucerne in areas where it has not been grown before. However, when Wigley et al. (2012) grew lucerne in a field with a paddock history of lucerne, peat-treated seed still gave the highest yields in the first regrowth year.

\section{Herbage quality}

The nitrogen content (N\%) of the lucerne was always above $3 \%$, which equates to adequate crude protein levels for animal production. Differences in N levels were only found for the 10 January 2013 harvest, when the $\mathrm{N} \%$ for SD1 was higher $(\mathrm{P}<0.05)$ than SD3 and SD4 (Figure 3a). In the September and October harvests, the peat treated seed had a higher $(\mathrm{P}<0.05) \mathrm{N} \%$ than the bare seed control (Figure $3 b$ ). These higher N\% values suggest $\mathrm{N}$ fixation occurred through spring in the peat treatments, but not in the bare seed controls. Increased temperatures probably led to increased rates of soil
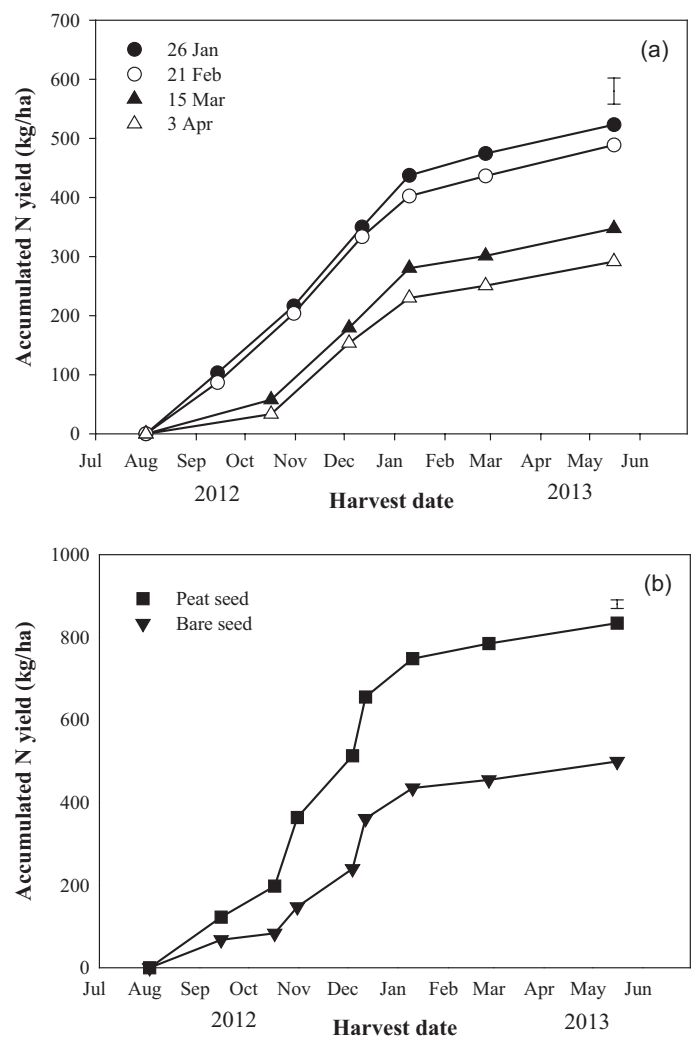

Figure 5 Accumulated $\mathrm{N}$ yield of 'Force 4' lucerne for the 2012/13 growth season when (a) sown on four different dates (2012) with (b) peat seed or bare seed seed treatments. Error bars are SEM for the main treatment effect shown.

$\mathrm{N}$ mineralisation from November on, which explains why there were no further differences between seed treatments.

Figure 4a shows the higher accumulated ME yields associated with the earlier autumn sowing dates. Figure $4 \mathrm{~b}$ shows the importance of inoculating lucerne seed when sowing into ground with no paddock history of lucerne. The accumulated ME yield for the peat-treated seed was $227 \mathrm{GJ} /$ ha compared $(\mathrm{P}<0.001)$ with the bare seed of $146 \mathrm{GJ} / \mathrm{ha}$.

Similarly the increased $\mathrm{N}$ yields from earlier sowing dates was expected (Figure 5a), as the plants had longer to use plant-available soil $\mathrm{N}$ and also fix N: SD1 yielded $523 \mathrm{~kg} \mathrm{~N} / \mathrm{ha}$, which was more $(\mathrm{P}<0.05)$ than SD3 and SD4. At the beginning of spring 2012, after a winter where $224 \mathrm{~mm}$ of rain fell, soil mineral $\mathrm{N}$ levels were on average $4 \mathrm{~kg} \mathrm{~N} / \mathrm{ha}$, irrespective of sowing date or seed treatment. $\mathrm{N}$ yields were higher $(\mathrm{P}<0.001)$ for the peat-treated seed (Figure 5b), which yielded 834 $\mathrm{kg} \mathrm{N} / \mathrm{ha}$ compared with the bare seed treatment which yielded $499 \mathrm{~kg} \mathrm{~N} / \mathrm{ha}$. It can therefore be estimated that the plants grown with peat-treated seed fixed 335 
$\mathrm{kg} \mathrm{N} / \mathrm{ha}$, which equates to $21 \mathrm{~kg} \mathrm{~N} /$ tonne $\mathrm{DM}$ grown above ground. Intensive $\mathrm{N}^{15}$ studies of white and sub clover have shown about $28 \mathrm{~kg} \mathrm{~N}$ fixed per tonne of DM grown (Lucas et al. 2010). The implication is that lucerne may fix $\mathrm{N}$ at lower rates than those Trifolium species, or have reduced $\mathrm{N}$ fixation in the presence of soil N.

\section{Perennial reserves}

By July 2012 there was a strong sowing date effect on root DM yield. The total root DM to a depth of $0.3 \mathrm{~m}$ for $\mathrm{SD} 1$ was $1550 \mathrm{~kg} \mathrm{DM} / \mathrm{ha}$, which was more $(\mathrm{P}<0.001)$ than $\mathrm{SD} 2$ at $828 \mathrm{~kg} \mathrm{DM} / \mathrm{ha}$. SD2 yielded more $(\mathrm{P}<0.001)$ than SD3, which yielded $112 \mathrm{~kg} \mathrm{DM} / \mathrm{ha}$ and SD4, which yielded only $32 \pm 10.4 \mathrm{~kg}$ DM. Taproots are an important storage organ in lucerne (Ourry et al. 1994), thus this lack of below ground biomass observed in SD3 and SD4 meant these plants had lowest reserves of nitrogen to draw on for early spring growth in 2012 . This probably caused the 33 day delay in the first harvest compared with the early sown crops. Analysis of root biomass in the top $50 \mathrm{~mm}$ of the root at July 2012 conveyed a similar picture. There was no effect of seed treatment on root biomass. By May 2013 the total root DM to a depth of $0.3 \mathrm{~m}$ also showed no effect of seed treatment. However, SD4 produced $4110 \mathrm{~kg}$ $\mathrm{DM} / \mathrm{ha}$, which was less $(\mathrm{P}<0.05)$ than the other sowing dates, which yielded an average of $5130 \pm 151 \mathrm{~kg} \mathrm{DM} /$ ha. This was also consistent with their lower spring yields and suggests they spent most of the following spring partitioning below-ground DM independently of photoperiod. The implication is that a juvenile phase may exist for lucerne where plant ontogeny overrides environmental signals (Teixeira et al. 2011). Given that perennial reserves were more consistent among crops at the end of year two, the effects of sowing date are expected to be lower in subsequent years.

\section{Conclusions}

With appropriate weed control and the use of fallowing, lucerne may be established successfully in late summer on dryland farms if spring sowing is not feasible. At Lincoln, mid-summer sowing in January and February led to higher yields in the first regrowth year compared with March and April sown crops. The effects of the later sowing manifest as lower yields in the first full year of regrowth.

When growing lucerne in New Zealand soils that have no history of lucerne cultivation, inoculation of lucerne seed prior to sowing is recommended. The benefits of inoculation were: increased DM yields and the introduction of $\mathrm{N}$ into the ecosystem from $\mathrm{N}$-fixation. The latter can increase soil fertility and farm production independently of inorganic nitrogen fertiliser. To date, all forms of inoculation treatment were superior to the bare seed control.

\section{ACKNOWLEDGMENTS}

Dr Annamaria Mills for assistance with experimental design and statistical analyses, and staff and technicians at the Field Service Centre, Lincoln, for their expertise and assistance.

\section{REFERENCES}

Blakemore, L.C.; Searle, P.L.; Daly, B.K. 1987. Methods for chemical analysis of soils. Revised Edition. N.Z. Soil Bureau Scientific Report No. 80. Department of Scientific and Industrial Research, Lower Hutt. 103 pp.

Carr, S.; Loi, A.; Vivas-Marfisi, A.I.; Poole, C. 2006. ALOSCA ${ }^{\circledR}$ A new technology to deliver rhizobia and other beneficial microbes into broadacre agriculture. pp. 10-14. In: "Groundbreaking Stuff". Proceedings of the 13th Australian Agronomy Conference.

Clough, T.J.; Stevens, R.J.; Laughlin, R.J.; Sherlock, R.R.; Cameron, K.C. 2001. Transformations of inorganic-N in soil leachate under differing storage conditions. Soil Biology and Biochemistry 33: 14731480.

Kear, B.S.; Gibbs, H.S.; Miller, R.B. 1967. Soils of the downs and plains Canterbury and North Otago New Zealand. New Zealand Soil Bureau Bulletin No. 14. Whitcombe \& Tombs Ltd, Wellington. 92 pp.

Khumalo, Q. 2012. Lucerne (Medicago sativa L.) establishment after inoculation with different carriers of Ensifer meliloti sown on five dates at Lincoln University. Masters of Science thesis. Lincoln University, Canterbury. Accessed 12/1/13: Online: http://hdl.handle.net/10182/4395

Lowther, W.L.; Kerr, G.A. 2011. White clover seed inoculation and coating in New Zealand. Proceedings of the New Zealand Grassland Association 73: 93-102.

Lucas, R.J.; Smith, M.C.; Jarvis, P.; Mills, A.; Moot, D.J. 2010. Nitrogen fixation by subterranean and white clovers in dryland cocksfoot pastures. Proceedings of the New Zealand Grassland Association 72: 141-146.

Moot D.J.; Pollock, K.M.; Lewis, B. 2012. Plant population, yield and water use of lucerne sown in autumn at four sowing rates. New Zealand Grassland Association 74: 97-102

Ourry, A.; Kim, T.H.; Boucaud, J. 1994. Nitrogen reserve mobilisation during regrowth of Medicago sativa L. Relationships between availability and regrowth yield. Plant Physiology 105: 831-837.

Teixeira, E.I.; Brown, H.E.; Meenken, E.D., Moot, D.J. 2011. Growth and phenological development patterns differ between seedling and regrowth lucerne crops (Medicago sativa L.). European Journal of Agronomy 35: 47-55 
Teixeira, E.I.; Moot, D.J.; Brown, H.E.; Pollock, K.M. 2007a. How does defoliation management impact on yield, canopy forming processes and light interception of lucerne (Medicago sativa L.) crops? European Journal of Agronomy 27: 154-164.

Teixeira, E.I.; Moot, D.J.; Mickelbart, M.V. 2007b. Seasonal patterns of root $\mathrm{C}$ and $\mathrm{N}$ reserves of lucerne crops (Medicago sativa L.) grown in a temperate climate were affected by defoliation regime. European Journal of Agronomy 26: 10-20.
Wigley, K.; Moot, D.J.; Khumalo, Q.; Mills, A. 2012. Establishment of lucerne (Medicago sativa) sown on five dates with four inoculation treatments. Proceedings of the New Zealand Grassland Association 74: 91-96.

Wynn-Williams, R.B. 1982. Lucerne establishment - conventional. pp. 11-19. In: Lucerne for the 80's. Special Publication No. 1. Ed. Wynn-Williams, R.B. New Zealand Agronomy Society, Palmerston North. 
